\title{
Synthetic Imagery for the Automated Detection of Rip Currents
}

\author{
Sebastian Pitman ${ }^{\dagger *}$, Shari L. Gallop ${ }^{\ddagger}$, Ivan D. Haigh ${ }^{\dagger}$, Sasan Mahmoodi ${ }^{\infty}$, Gerd Masselink ${ }^{\S}$ and Roshanka \\ Ranasinghe $^{\dagger \dagger}$ \\ ${ }^{\dagger}$ Ocean and Earth Science, National Oceanography \\ Centre, University of Southampton, UK. \\ ${ }^{\infty}$ School of Electronics and Computer Science, University of \\ Southampton, UK \\ \$Department of Environmental Sciences, Macquarie \\ University, Sydney, NSW, Australia.

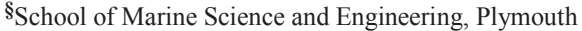 \\ University, UK. \\ www.cerf-jcr.org
}

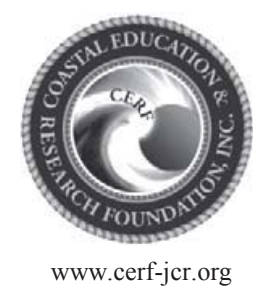

"UNESCO-IHE and Deltares, Delft, The Netherlands; and

Australian National University, Canberra, Australia.

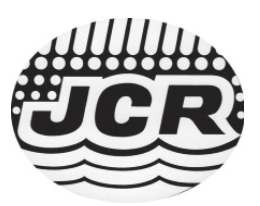

www.JCRonline.org

\begin{abstract}
Pitman, S.J.; Gallop, S.L.; Haigh, I.D.; Mahmoodi, S.; Masselink, G., and Ranasinghe, R., 2016. Synthetic imagery for the automated detection of rip currents. In: Vila-Concejo, A.; Bruce, E.; Kennedy, D.M., and McCarroll, R.J. (eds.), Proceedings of the 14th International Coastal Symposium (Sydney, Australia). Journal of Coastal Research, Special Issue, No. 75, pp. 912-916. Coconut Creek (Florida), ISSN 0749-0208.

Rip currents are a major hazard on beaches worldwide. Although in-situ measurements of rips can be made in the field, it is generally safer and more cost effective to employ remote sensing methods, such as coastal video imaging systems. However, there is no universal, fully-automated method capable of detecting rips in imagery. In this paper we discuss the benefits of image manipulation, such as filtering, prior to rip detection attempts. Furthermore, we present a new approach to detect rip channels that utilizes synthetic imagery. The creation of a synthetic image involves the partitioning of the 'parent' image into key areas, such as sand bars, channels, shoreline and offshore. Then, pixels in each partition are replaced with the respective dominant color trends observed in the parent image. Using synthetic imagery increased the accuracy of rip detection from $81 \%$ to $92 \%$. Synthetics reduce 'noise' inherent in surfzone imagery and is another step towards an automated approach for rip current detection.
\end{abstract}

ADDITIONAL INDEX WORDS: rip channel, image filtering, remote sensing, coastal imaging, synthetic imagery.

\section{INTRODUCTION}

Rip currents (rips) are seaward-orientated, jet-like flows originating in the surfzone (Short, 1985). They generally occur in channels incised into sand bars (Shepard et al., 1941; Bowen, 1969). Despite numerous field campaigns, studies have been unable to relate rip behaviour solely to the incident wave field, due to factors such as nonlinearity, time-lags, and the largely unknown effects of antecedent bathymetry (e.g., Holman et al., 2006; Huntley and Short, 1992; Short, 1985). The inability to linearly link forcing and response of rip channels has resulted in a somewhat site-specific understanding on the key controls on rips. The main cause for this knowledge gap is the lack of adequate, long-term field data at multiple sites with different forcing. Field experimentation in the surfzone is difficult, expensive, and often dangerous. Therefore, remote sensing provides an attractive alternative.

Video imaging has been used to remotely sense the nearshore for about 25 years. Lippmann and Holman (1989) first realised the utility of time-lapse imagery in identifying the position of offshore sand bars, using areas of high light intensity generated by waves breaking over the bar. The development of bespoke coastal imaging methods such as Argus (Holman and Stanley, 2007), allows extraction of quantitative data from images. Such information includes bar position (Lippmann and Holman, 1989),

DOI: 10.2112/SI75-183.1 received 15 October 2015; accepted in revision 15 January 2016

*Corresponding author: sjp1e13@soton.ac.uk

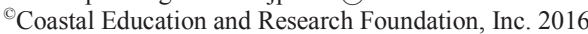

wave period and nearshore bathymetry (Ranasinghe et al., 2004; Stockdon and Holman, 2000), wave incidence angle (Lippmann and Holman, 1991), and alongshore rip channel locations (Ranasinghe et al., 1999).

Video imaging has been used to detect and measure rip channel parameters, such as quantity and alongshore location (e.g., Ranasinghe et al., 1999). These techniques were used to extract datasets of up to 4 years (e.g., Holman et al., 2006); timescales that would be unfeasible to measure in-situ. A major limiting factor on the length of rip datasets that can be generated is that all attempts thus far required various degrees of manual input (Bogle et al., 2000; Gallop et al., 2009; Holman et al., 2006; Quartel, 2009; Ranasinghe et al., 1999; Turner et al., 2007; Whyte et al., 2005). The majority of research using video images uses the raw image products (snapshot, timex, daytime, etc.) output from the cameras, which can often be inherently 'noisy', hindering robust rip channel detections.

Therefore, this research aims to investigate the merits of image manipulation, prior to the extraction of data from imagery. In particular, we consider the benefits of spatial filtering, and the use of synthetic images as it may provide an intermediate step overcoming previous problems with automated rip detection.

\section{Image-Based Rip Detection}

The favoured approach to date for automatic rip detection has been to use pixel intensity minima as indicative of rip channel location, because deeper channels appear as darker areas between the higher intensity wave breaking zones over shoals. It is also common to average the intensity values in the cross-shore 
direction. All values between the shoreline and the edge of the breaking region are averaged at each alongshore position, to compute one alongshore intensity profile (Ranasinghe et al., 1999). This method is appropriate for simple scenarios, where rip channels are orientated in shore-normal directions. It is inappropriate for complex bathymetries (Holman et al., 2006) such as the common cases where rip channels cut across the surfzone diagonally to form acute angles with the shoreline.

The intensity profiles generated have typically been subject to visual classification in order to ascertain rip locations (e.g., Bogle et al., 2000). This is due to the resultant image intensity profiles containing a degree of 'noise' or 'fouling' that can act to obscure the main features. In this context, noise refers to artefacts introduced to the image during processing. Fouling refers to anything undesirably captured by the camera, such as rain drops and fog. Noise can be present in the image for a variety of reasons, such as environmental factors (i.e. sensor temperature) during image acquisition (Russ, 2007).

Analogue signals of the natural world are continuos (Bovik, 2005 ) and therefore need to be quantized to produce digital images before computer processing. In the literature pertaining to image-based rip detection and surfzone studies, pixel values know as intensities are usually quantized into 256 discrete levels [0-255]. This quantization process introduces a uniform noise to the digital image (Gonzalez and Woods, 2008). A common approach to reduce such noise in the field of image processing is to filter the image, yet this is rarely discussed in literature pertaining to image-based rip detection, or surfzone studies.

\section{Image Filtering \& Manipulation}

To our knowledge, simple single-image filtering of nearshore images has not been widely used before, because the prevalent image type used for analysis is the so called timex image, which represents the time-mean of intensity in all frames collected at 2 $\mathrm{Hz}$ over a 10-minute period (Holman and Stanley, 2007). This constitutes a form of average filtering during the image acquisition stage; however, the resultant image may still include background noise or erroneous data. One such example is raindrops on the lens covering, which would appear in the rectified image, giving a false intensity signature for the pixel(s) concerned. Studies using video images tend to reject imagery where raindrops are visible on the lense for this reason. Holman et al. (2013) described how consecutive images in a time series can be used to create a running-average estimate (cBathy). cBathy uses wave celerity to estimate bathymetry, and the use of this running-average filter has been successful in removing fouling from subsequent images, such as rain drops or sun glare. Despite the assumption that a timex image is already prefiltered, it still contains noisy signals, representative of a very dynamic surfzone. Furthermore, inclement weather still appears as fouling in the imagery. Therefore, there is a need to pre-filter the image before processing, rather than relying on filtering the signal that is extracted as a result of processing.

\section{METHODS}

In this study we use images from Tairua beach in New Zealand, to investigate the benefit of simple spatial filtering, as well as the use of synthetic images for rip channel detection.

\section{Field Site}

Tairua beach, is located on the Coromandel Peninsula of New Zealand's North Island. This site was chosen because it exhibits a range of surfzone morphologies. Tairua is a 1,200 m-long embayment confined by a rocky promontory in the north, and an extinct volcano in the south (Figure 1). The beach faces east and receives medium energy $\left(H_{s}=1.5 \mathrm{~m} ; T_{m}=10 \mathrm{~s}\right)$ waves from the South Pacific (Almar et al., 2008). The beach generally exhibits an intermediate state (Masselink and Short, 1993), and is comprised of medium-coarse $\left(D_{50} \approx 0.6 \mathrm{~mm}\right)$ sands (van de Lageweg et al., 2013). The tidal regime is predominantly microtidal, with a range varying between $1.2 \mathrm{~m}$ (neap) and $2.0 \mathrm{~m}$ (spring) (van de Lageweg et al., 2013). The beach is monitored under the New Zealand National Institute of Water and Atmospheric Research (NIWA) Cam-Era scheme, which has collected images here since 1999. The camera is mounted at the southern end of the beach, at a height of $68 \mathrm{~m}$ above mean sea level (van de Lageweg et al., 2013).

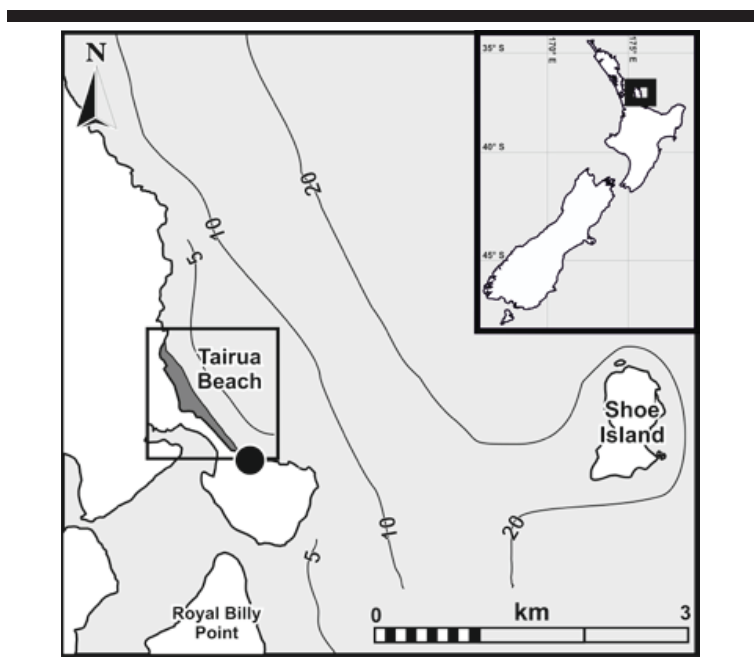

Figure 1. Map of Tairua study site (black box), including the location of the Cam-Era monitoring station (black circle).

\section{Image Filtering}

The first stage to create a synthetic image is filtering the parent image. A common approach to filtering is the use of highand low-pass filters. These operate in the frequency domain of the image, akin to Fourier transforms. High frequency noise is introduced to imagery by sharp intensity transitions, such as edges observed at the shoreline. These high frequency signals can be smoothed using a lowpass filter, attenuating the high frequency components and therefore blurring the image (Gonzalez and Woods, 2008).

In simple cases, where only a few raindrops have fouled the image, spatial filtering can remove the effect of this noise. When the fouled image is rectified, the previously small element of noise (the rain drop), is projected across a wide area (e.g., Figure $2 \mathrm{a})$, as a result of the transformation between image co-ordinates $[\mathrm{u}, \mathrm{v}]$ and real-world co-ordinates $[\mathrm{x}, \mathrm{y}, \mathrm{z}]$. A Gaussian lowpass 
filter (mask $=15 \times 15, \sigma=10)$ is applied to the rectified image (Figure 2b). Subsequently, pixel intensities from the same transect of pixels in each image are extracted (Figure 2c). The maximum gradient in intensity profile is used as an estimation of the onset of wave breaking. In the unfiltered image, large errors are evident in the detected location of wave breaking (Figure 2d) wherever rain fouls the lens. In contrast, the errors do not exist in the profile extracted from filtered imagery.

This example highlights the benefits to be gained from image manipulation prior to processing, such as the removal of small patches of lens fouling. As these sharp intensity transitions are often expected to represent the very feature we wish to investigate, such as the edge of a rip channel, filtering can smooth these features yielding more accurate results.
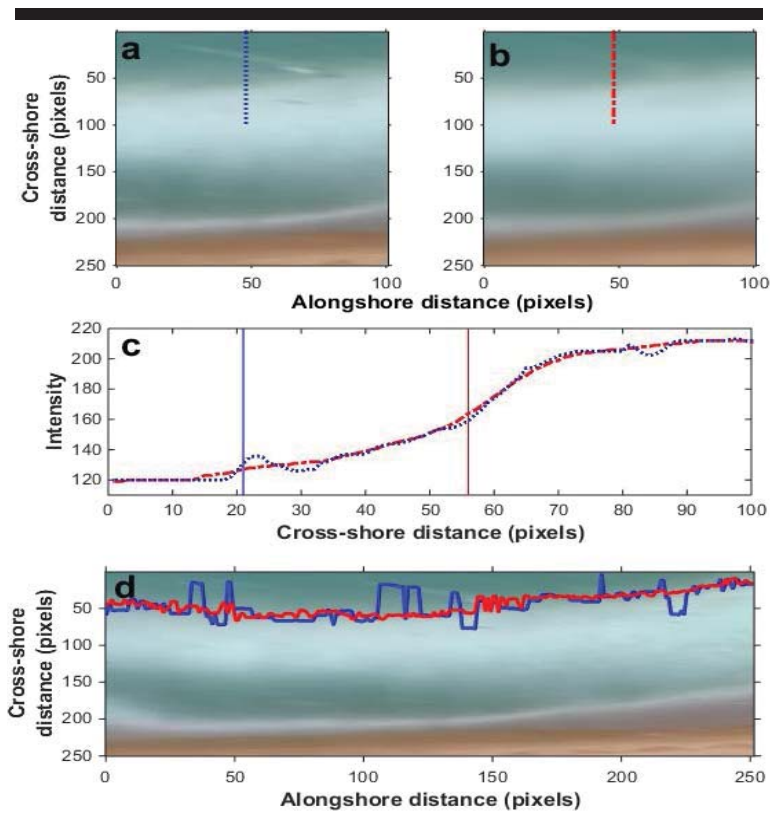

Figure 2. (a) Rectified timex image of Tairua beach, New Zealand. Rain drop fouling is evident in the region of the blue transect line. (b) Filtered version of (a) with red transect line. (c) Intensity profiles for both transect lines, with the maxima marked by horizontal lines. (d) Onset of wave breaking detected alongshore using intensity maxima transects, as per (c).

\section{Synthetic Image Creation}

Having filtered the parent image, the next stage is to segment it into distinct zones: beach, rip channels, breaking waves, and offshore. Rip channels and breaking waves form the surfzone. The offshore boundary of the surfzone is the limit of wave breaking which is defined by the first significant increase in the pixel intensity gradient (Bogle et al., 2000). The landward boundary of the surfzone is determine by the shoreline. This is detected using segmentation based on 3-banded k-means clustering (Wang and Adelson, 1994). This method identifies the beach by the dominance of the red pigmentation in the RGB signature. The surfzone must then be separated into rip channels and wave breaking regions. This is done by thresholding the extreme intensity values, and using the mid-point as a cut-off.

The image is now composed of 4 distinct zones (Figure 3b). All pixel values for each individual zone are collated, and used to create zone-specific histograms of red, green and blue pigments (Figure 3c-f). For each zone, the pixels are replaced with synthetic pixels. These synthetic pixels are generated from the normal distribution created in the previous stage. The pixel value is random, but weighted towards the higher probability occurrences from the distribution curve.

In order to estimate the utility of synthetic imagery for improved methods of automated rip detection, this study applies the rip detection method proposed by Ranasinghe et al. (1999) to both the original rectified imagery, and the corresponding synthetic image. The original image is manually digitized in a similar method to that described by Whyte et al. (2005) as a benchmark to assess the accuracy of the rip detection algorithm. The errors of such digitisation are documented in Holman et al. (2006), who report that two users digitising rips on average recorded the same number of rips in the imagery per day, but the recorded location of rips was more variable between digitizers. For the purposes of this study, the more consistent rip number parameter is used. The images selected are a random selection of 80 images from the archive.

\section{RESULTS}

Both image types produce a statistically significant (at 95\%) correlation in the quantity of rips. Correlation in the original imagery $(\mathrm{R}=0.28, \mathrm{P}=0.013)$ is poorer than that in the synthetic detections $\left(\mathrm{R}=0.47, \mathrm{P}=1.2 \times 10^{-5}\right)$. The correlation in synthetic imagery was statistically significant at $99 \%$. Correlation alone is not a good measure of agreement; therefore, the error in each method has been presented here.

The user-digitized number of rips in each image varies between 1 and 4 (Figure 4). A nominal 'acceptable error' threshold of \pm 1 detected rip is plotted onto Figure 4 . In total, the original imagery produces correct detections $34 \%$ of the time, compared to $41 \%$ in the synthetic imagery. The detections lay inside of the \pm 1 error threshold $81 \%$ of the time in the original imagery, compared to $92 \%$ of the time in the synthetic imagery, resulting in total error $(> \pm 1)$ in $19 \%$ of the original image detections, and $8 \%$ of the synthetic detections.

Of the detections that were incorrect in the original imagery (66\%), 38\% were under-predictions, compared to $62 \%$ overpredictions. The opposite is true of the synthetic imagery $(59 \%$ incorrect), whereby $64 \%$ of erroneous detections were underpredictions and $36 \%$ were over-predictions.

In the original imagery, in all 4 scenarios (1 - 4 digitized rips), the standard deviations in the detection lie outside of the \pm 1 error threshold (Figure 4a), whereas only one scenario (4 rips) contains standard deviations outside this threshold in the synthetic imagery. Interestingly, both methods produce an under-estimation of comparable magnitude in the 4 rip scenario.

\section{DISCUSSION}

In this paper we have shown that simple image filtering can reduce small-scale fouling and noise in imagery. Previously, the signal extracted from the raw image would generally be filtered, 
as opposed to filtering the image first. This is important as the extracted signal through a set of pixels is generally 1-directional and does not take account of neighbouring pixels and trends. The filtering of an image, rather than extracted signal, uses 2dimensional filters and local pixel statistics to remove noise (Lee, 1980). This filtered image is then ready for quantitative analysis, or here, the creation of a synthetic image. We have also shown that the use of synthetic imagery as opposed to original images improves rip detection using the method outlined by Ranasinghe et al. (1999). The total error in detections with synthetics is halved when compared to original imagery.

The reported limitations of the Ranasinghe et al. (1999) method (Holman et al., 2006; Turner et al., 2007) were clear in the results, as detections on both the original and synthetic images produced considerable scatter. This is likely the result of the complex rip channel morphologies at Tairua, where rips orientated shore-normally are a minority occurrence. That said, there are significantly fewer rips detected in the synthetic imagery $(n=203)$, compared to the original imagery $(n=242)$, which infers that the synthetic images provide a dataset with much less unrelated extraneous noise.

The method used for rip detection oversimplifies the morphology qualitatively observed in the imagery, and therefore, it is expected that any results obtained via this method would under predict the occurrence of rip channels. Despite the oversimplification inherent in the method, detections based on the original imagery still produces over-estimation of rip number $41 \%$ of the time, which is perhaps indicative of the amount of noise the original image contains. In comparison, the synthetic imagery produces under-estimation (as would be expected using this method) on $38 \%$ of detections.

The work of Bogle (2000) used the same approach as Ranasinghe et al. (1999) on Tairua, but ultimately resorted to visual selection of intensity minima. This is presumably because the complex patterns observed in imagery made automation via the use of thresholds (such as in our approach using original imagery) unviable. The use of a simplified synthetic-type image may aid steps towards an automated approach to rip detection. We have shown here, for the same study site that the simplification of the imagery via the creation of a synthetic image, increases the number of correct detections, and also the number of predictions correct to within \pm 1 rip. This new intermediate step may help overcome the documented limitations of current attempts to automatically detect rip channels in imagery.

\section{CONCLUSIONS}

This research investigated the effect of image manipulation, in the form of image filtering and synthetic image creation, on automated rip channel detection in surfzone imagery. Simple filtering methods were able to reduce the effects of small scale fouling and noise on image intensity signals. The use of synthetic imagery increased rip detections within the acceptable error threshold from $81 \%$ correct to $92 \%$. Rip channel detection using synthetic imagery reduced the total number of detections by $16 \%$, showing a reduction of extraneous noise inherent with the original image. A systematic underprediction was observed in the detection of rips using synthetic imagery, which is consistent with the detection method selected. This paper provides proof of concept for image manipulation prior to
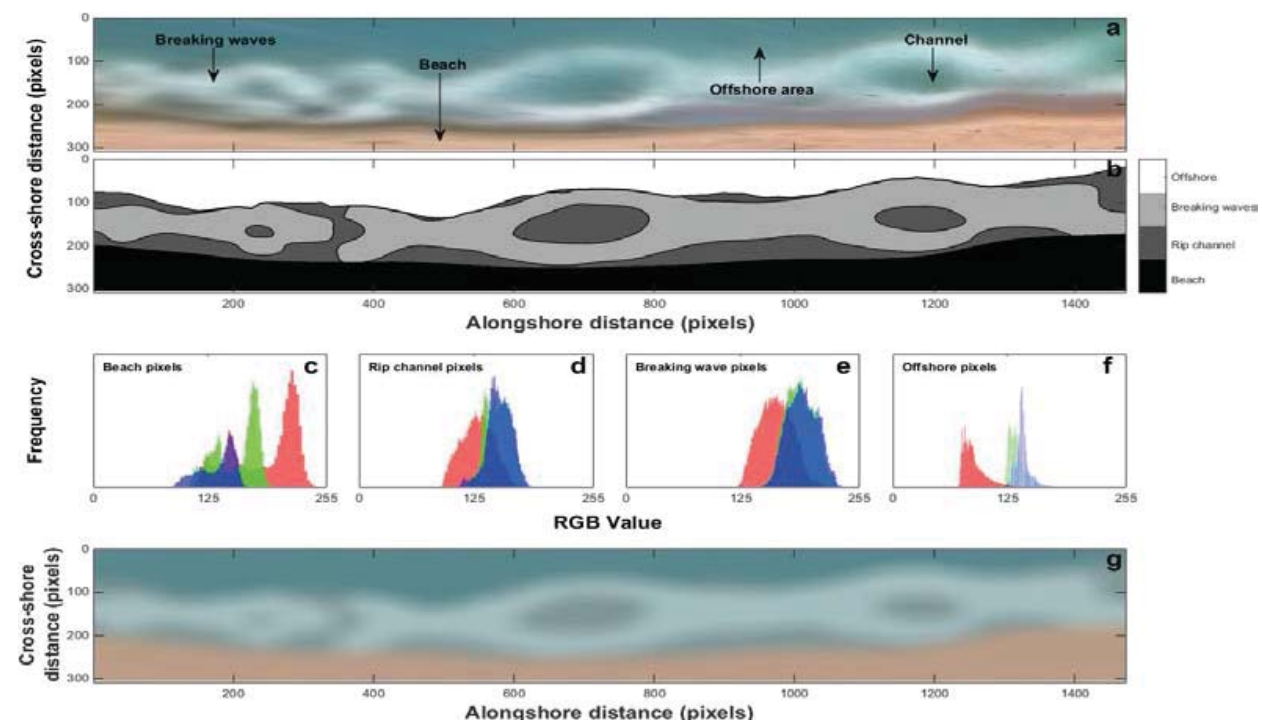

Figure 3. (a) An original rectified image from Tairua beach. (b) The parent image (a) has been segmented into the offshore region, the beach, and then within the surfzone into areas of wave breaking, and deeper channeled areas. (c-e) The pixel values from the original image (a) for each zone identified in (b) have been extracted, and presented in terms of their red, green, and blue pixel values. The zones in (b) are then filled with pixels randomly selected from the corresponding pixel value distribution curve in (c-f). The resulting image is the synthetic image, with each zone now exhibiting the dominant colour trend observed in the parent image. 

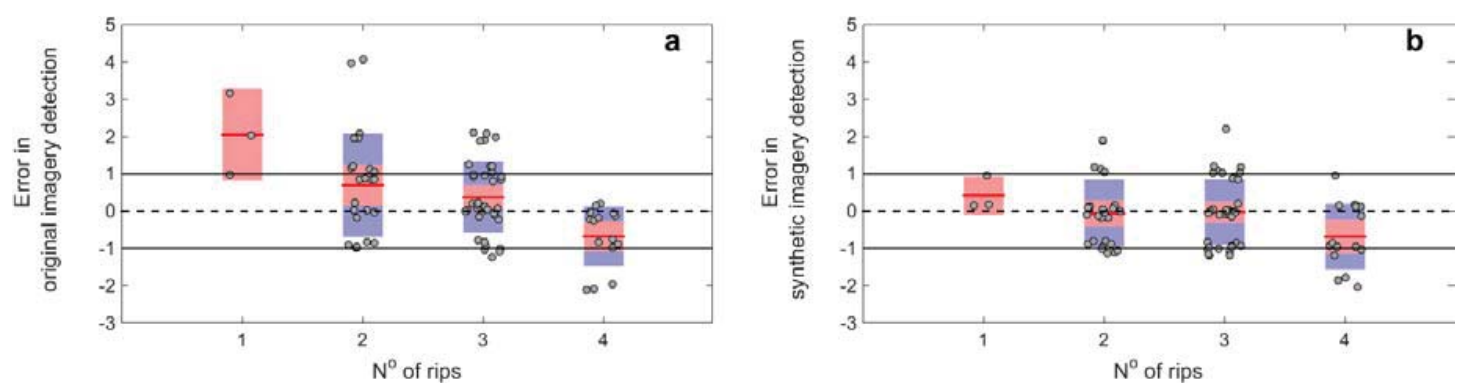

Figure 4. The user-digitized number of rips in each image obtained by digitization compared to the error in the number of rips detected in the corresponding original image (a) and synthetic image (b). Positive and negative numbers represent over- and under-predictions, respectively. Each prediction is represented as a scatter point. The data is binned by the user-digitized number of rips, with the mean (red line), the 1.96 standard error of the mean for each class (red bar), and the standard deviation (blue bar).

processing, in order to aid automated surfzone feature detection.

\section{ACKNOWLEDGEMENTS}

The authors acknowledge Waikato Regional Council and NIWA for the provision of Cam-Era images presented in this study. Thanks to Karin Bryan (University of Waikato) for help with image rectification. RR is supported by the AXA Research fund and the Deltares Deltares Harbour, Coastal and Offshore engineering Research Programme 'Bouwen aan de Kust'.

\section{LITERATURE CITED}

Almar, R.; Coco, G.; Bryan, K.; Huntley, D.; Short, A., and Senechal, N., 2008. Video observations of beach cusp morphodynamics. Marine Geology. 254, 216-223.

Bogle, J.; Bryan, K.; Black, K.; Hume, T. and Healy, T., 2000. Video Observations of Rip Formation and Evolution, in Healy, (ed) Proceedings, International Coastal Symposium 2000. Journal of Coastal Research, SI 34, 117-127.

Bovik, A.C., 2005. Introduction to digital image and video processing, in: Bovik, A. (Ed.), Handbook of Image and Video Processing., USA: Elsevier, pp. 3-20.

Bowen, A.J. 1969. Rip currents 1: Theoretical observations Journal of Geophysical Research, 74, 5467-5478.

Gallop, S.L.; Bryan, K.R., Coco, G., 2009. Video observations of rip currents on an embayed beach, in: Da Silva (ed) Proceedings, International Coastal Symposium 2009. Journal of Coastal Research, Special Issue No. 56, pp. 49-53.

Gonzalez, R.C. and Woods, R.E., 2008. Digital Image Processing, 3rd ed. USA: Pearson.

Holman, R.A.; Plant, N.G. and Holland, K.T., 2013. cBathy: A robust algorithm for estimating nearshore bathymetry. Journal of Geohpysical Research, 118(5), 2595-2609.

Holman, R.A. and Stanley, L., 2007. The history and technical capabilities of Argus. Coastal Engineering, 54, 477-491.

Holman, R.A.; Symonds, G.; Thornton, E.B. and Ranasinghe, R., 2006. Rip spacing and persistence on an embayed beach. Journal of Geohpysical Research 111, C01006.

Huntley, D.A., and Short, A.D., 1992. On the spacing between observed rip currents, Coastal Engineering. 17, 211 - 225.

Lee, J-S., 1980. Digital image enhancement and noise filtering by use of local statistics. IEEE Transactions on pattern analysis and machine intelligence, PAMI-2 (2), 165-168.
Lippmann, T.C. and Holman, R.A., 1991. Phase Speed and Angle of Breaking Waves Measured with Video Techniques, in: Coastal Sediments (1991). ASCE, pp. 542-556.

Lippmann, T.C. and Holman, R.A., 1989. Quantification of Sand Bar Morphology: A Video Technique Based on Wave Dissipation. Journal of Geohpysical Research, 94, 995-1011.

Masselink, G. and Short, A.D., 1993. The effect of tide range on beach morphodynamics and morphology: A conceptual beach model. Journal of Coastal Research, 9, 785-800.

Quartel, S., 2009. Temporal and spatial behaviour of rip channels in a multiple-barred coastal system. Earth Surface Proceeses and Landforms, 34, 163-176.

Ranasinghe, R.; Symonds, G. and Holman, R.A., 1999. Quantitative characterisation of rip currents via video imaging, in: Kraus, N.C., McDougal, W.G. (eds.), Coastal Sediments '99. American Society of Civil Engineers, Reston, USA, pp. 987-1002.

Ranasinghe, R.; Symonds, G.; Black, K. and Holman, R.A., 2004. Morphodynamics of intermediate beaches: a video imaging and numerical modelling study. Coastal Engineering. 51, 629-655.

Russ, J., 2007. Image processing handbook, USA: CRC Press.

Shepard, F.; Emery, K. and LaFond, E., 1941. Rip currents: a process of geological importance. J. of Geology, 49, 337-369.

Short, A.D., 1985. Rip current type, spacing and persistence, Narrabeen Beach, Australia. Marine Geology. 65, 47-71.

Stockdon, H.F. and Holman, R.A., 2000. Estimation of wave phase speed and nearshore bathymetry from video imagery. Journal of Geohpysical Research 105, 22015-22033.

Turner, I.L.; Whyte, D.; Ruessink, B.G. and Ranasinghe, R. 2007. Observations of rip spacing, persistence and mobility at a long, straight coastline. Marine Geology. 236, 209-221.

Van de Lageweg, W.I.; Bryan, K.R.; Coco, G. and Ruessink, B.G., 2013. Observations of shoreline-sandbar coupling on an embayed beach. Marine Geology. 344, 101-114.

Wang, J. and Adelson, E., 1994. Represent moving images with layers. IEEE Transactions on Image Processing. 3, 625-638.

Whyte, D.; Turner, I.L. and Ranasinghe, R., 2005. Rip Characterisation on the Gold Coast, Australia: An Analysis using Coastal Imaging Techniques, in: Coasts and Ports 2005: Coastal Living - Living Coast. Adelaide, Australia. 